\title{
Initial Body Mass Index on Weight Loss Among Obese Filipino Adults Who Underwent Laparoscopic Adjustable Gastric Banding: A Cohort Study
}

\author{
Teodora Amor Evora, ${ }^{1}$ Roberto Mirasol, ${ }^{1}$ Edward Oliveros,${ }^{2}$ Hildegardes Dineros ${ }^{2}$ \\ ${ }^{1}$ Section of Endocrinology and Metabolism, Department of Internal Medicine, St. Luke's Medical Center, Philippines, Quezon City, Philippines \\ ${ }^{2}$ Department of Surgery, St. Luke's Medical Center, Quezon City, Philippines
}

\begin{abstract}
Objective. To determine the effect of laparoscopic adjustable gastric banding (LAGB) on weight loss and the association between initial body mass index (BMI) and successful weight loss, defined as $>50 \%$ excess weight loss (EWL) among obese Filipino adults at St. Luke's Medical Center.

Methodology. Data from 97 patients who were at least 18 years old at the time of gastric banding were reviewed retrospectively. Patient follow-up was poor 2 years post-surgery, which precluded analysis of follow-up data beyond 2 years. Changes in weight loss parameters from baseline to the different observation periods were carried out using paired t- test. To determine the association of different factors with success in weight loss, Independent t-test and Chisquare tests were used. A p-value $\leq 0.05$ was considered significant.
\end{abstract}

Results. Majority of the patients were female (61\%) and Southeast Asian (77\%). Ages ranged from 18 to 68 years. Mean BMI was $44.1 \pm 0.1 \mathrm{~kg} / \mathrm{m}^{2}$ and mean excess weight was $61.4 \pm 26.5 \mathrm{~kg}$. Excess weight loss of $43.84 \pm 25.09 \%$ and BMI reduction of $21.54 \pm 13.39 \%$ were attained at 2 years. Lower initial BMl with a mean of $38.12 \pm 3.28 \mathrm{~kg} / \mathrm{m}^{2}$ was associated with successful weight loss, 1 year after gastric banding $(p<0.001)$.

Conclusion. Patients attained $43.84 \%$ EWL 2 years after gastric banding. Those with higher initial BMI were less likely to achieve successful weight loss 1 year after gastric banding.

Keywords: laparoscopic adjustable gastric banding, bariatric surgery, obesity, weight loss

\section{INTRODUCTION}

The global epidemic of obesity, its impact on morbidity and mortality, and the limited availability of safe and effective therapeutic options have made bariatric surgery a widely accepted treatment option. It is currently the most effective treatment for obesity and its associated comorbidities. ${ }^{1,2,3}$ However, it is not a guarantee of successful weight loss and maintenance. With an increasing number of patients undergoing bariatric surgery, there is a concomittant rise in postoperative metabolic and nutritional complications. The clinical dilemma is how to select a suitable surgical candidate and the appropriate surgical procedure for each patient. Endocrinologists should be aware of these challenges as they become active participants in the surgical management team.

Of the current surgical weight loss procedures, laparoscopic adjustable gastric banding (LAGB) is widely used because it is the least invasive, has good overall results with the fewest complications and is reversible., ${ }^{4,5}$

ISSN 0857-1074

Printed in the Philippines

Copyright (C) 2013 by the JAFES

Received April 2, 2012. Accepted April 23, 2013.
In our institution, it is the most commonly performed bariatric procedure. ${ }^{6,7}$ However, LAGB and other purely restrictive operations result in lower-than-expected average weight loss, higher weight regain and less resolution of comorbidities, compared to malabsorptive surgical procedures, exemplified by gastric bypass and biliopancreatic diversion (BPD). ${ }^{1,5}$ Unlike the metabolic effects of malabsorptive procedures that are independent of weight loss, the resolution or improvement in comorbidities after LAGB is dependent on the amount of weight loss. ${ }^{5}$ Therefore, we sought to determine the effect of LAGB on weight loss among obese Filipino adults at St. Luke's Medical Center, a tertiary referral hospital in the Philippines.

An excess weight loss of more than 50\% has been commonly associated with resolution or improvement of comorbidities after LAGB. As such, it is viewed as a measure of successful weight loss. ${ }^{1}$ Several factors that influence the attainment of successful weight loss after LAGB have been identified. Higher initial BMI has been demonstrated in some studies to be inversely related to

Corresponding author: Teodora Amor N. Evora, MD

Diabetes, Thyroid and Endocrine Center

12th floor, Cathedral Heights Building

St. Luke's Medical Center

E. Rodriguez Avenue, Quezon City, Philippines

Tel./Fax No.: 7230101 local 5210

E-mail:amorevora@gmail.com 
the percentage of excess weight loss (\%EWL); in others, it was found to have no influence..$^{8,9,10,11}$ For this reason, we also aim to determine the association between initial BMI and successful weight loss after LAGB.

We also present the demographic and metabolic characteristics of patients at the time of LAGB, follow-up data at specific time intervals after surgery, \%EWL and percent change in body mass index (\%BMIL) after LAGB, successful weight loss or attainment of more than $50 \%$ EWL according to age and BMI categories, and the association between patient characteristics (baseline BMI, age, sex, smoking) and successful weight loss after gastric banding in our institution. By presenting these outcomes, we may be able to set realistic expectations for patients electing to undergo LAGB. Physicians actively involved in obesity treatment may apply the results of the study in selecting appropriate candidates for LAGB. The results may also set a benchmark for future outcome studies on LAGB in the Philippine setting.

\section{METHODOLOGY}

Bariatric surgery was first performed in our institution in March 2002. Of the 212 patients who had undergone bariatric surgery as primary surgical treatment for obesity from March 2002 to December 2009, we identified 136 patients who underwent LAGB. We excluded patients who underwent the procedure from March 2002 to December 2003-when the surgical techniques and type of adjustable gastric bands used were still undergoing modification and improvement-in order to have a homogeneous population. After excluding earlier cases, 114 eligible patients with uniform surgical technique and gastric band, who underwent LAGB between 01 January 2004 and 31 December 2009, were identified. Patients aged 18 years and older with at least one weight measurement during the post-operative period were included in the study. This led to the selection of 97 patients.

The indications for bariatric surgery in our institution were adapted from guidelines given by the American Association of Clinical Endocrinologists, The Obesity Society and the American Society of Metabolic and Bariatric Surgery, and from the Interdisciplinary European Guidelines on Surgery of Severe Obesity. ${ }^{12,13}$ Patients with BMI of $40 \mathrm{~kg} / \mathrm{m}^{2}$ and greater who have failed to lose weight or to maintain weight loss despite appropriate medical management are eligible candidates for bariatric surgery. Patients with BMI of 35 to $39 \mathrm{~kg} / \mathrm{m}^{2}$ with one or more severe obesity-related comorbidities are also offered bariatric surgery. ${ }^{12,13}$

In addition to LAGB, other bariatric surgical procedures performed in our institution include Roux-en- $Y$ gastric bypass and BPD with or without duodenal switch. Currently, there is insufficient evidence to aid in the selection of the appropriate procedure for each patient. ${ }^{12.13}$ The choice of the type of bariatric procedure in our institution depends on the expertise of the surgeon, patient preference and risk stratification, among other factors. Preoperative factors that may influence the selection of the type of operation include BMI; age; gender; body fat distribution; conditions such as type 2 diabetes mellitus (T2DM), dyslipidemia, binge-eating disorders, significant hiatal hernia and gastroesophageal reflux disease; and the patient's expectations and realistic goals. ${ }^{13}$

\section{Study design}

A retrospective cohort study was conducted to analyze the effects of LAGB and association of BMI with weight loss among patients who underwent the procedure from January 2004 to December 2009. Data collection was done by reviewing medical records during admission for LAGB and on follow-up at the surgeon's clinic. The data included age, gender, race, height, baseline and follow-up weight and BMI, and baseline comorbidities. Data on eating behavior, physical activity, lifestyle changes, port- or band-related complications and resolution of comorbidities were either incomplete or unavailable.

\section{Preoperative process}

Each patient underwent preoperative evaluation by an endocrinologist, bariatric surgeon, cardiologist, pulmonologist and psychiatrist, and was subsequently given pre- and postoperative nutritional and dietary advice. All patients were screened to exclude endocrine causes of obesity.

Preoperative laboratory tests were performed to determine comorbidities before band placement. Preexisting or newly diagnosed T2DM was defined as fasting blood sugar (FBS) of $7 \mathrm{mmol} / \mathrm{L}(126 \mathrm{mg} / \mathrm{dL})$ or greater, 2-hour plasma glucose in a 75-gram oral glucose tolerance test (OGTT) of $11.1 \mathrm{mmol} / \mathrm{L}(200 \mathrm{mg} / \mathrm{dL})$ or greater, glycosylated hemoglobin (HbA1c) of $6.5 \%$ or greater, or known diagnosis and/or treatment for T2DM. Prediabetes was defined as FBS of 5.6 to $6.9 \mathrm{mmol} / \mathrm{L}$ (100 to $125 \mathrm{mg} / \mathrm{dl})$, 2-hour plasma glucose in a 75-gram OGTT of 7.8 to 11.0 $\mathrm{mmol} / \mathrm{L}$ (140 to $199 \mathrm{mg} / \mathrm{dl}$ ), and/or HbA1c of 5.7 to $6.4 \%{ }^{14}$ Dyslipidemia was defined as an abnormality of at least one component in the lipid profile, known diagnosis and/or treatment for dyslipidemia. Low density lipoprotein-cholesterol (LDL-C), high density lipoproteincholesterol (HDL-C) and triglyceride levels were considered abnormal if values outside the target goals set by the National Cholesterol Education Program Expert Panel for particular risk groups. ${ }^{15}$ The diagnosis of hypertension was based on elevated blood pressure or known diagnosis and/or treatment for hypertension; cardiovascular disease, on electrocardiography or echocardiography; sleep apnea on sleep studies, or known diagnosis and/or treatment for sleep apnea; fatty liver on liver ultrasonography; and cholelithiasis on gallbladder ultrasonography and/or prior history of cholecystectomy. 


\section{Operative management}

All operations were performed by either one of 2 surgeons at the institution using the same adjustable gastric band and operative technique. Upon discharge, patients were instructed to adhere to a liquid diet for 4 weeks, and a solid diet thereafter.

\section{Postoperative management}

Postoperative management involved scheduled visits for in-office band adjustments, education and counselling. Specific requirements included office visits every 4 to 6 weeks during the first 6 months, quarterly during the next 6 months, then annually thereafter. Some patients were unable to comply with scheduled office visits due to residency overseas.

\section{Standardized follow-up time intervals}

We followed standardized time intervals for reporting bariatric surgical outcomes: 3 months ( \pm 3 months), 1 year ( \pm 6 months), 2 years ( \pm 6 months), and yearly ( \pm 6 months) thereafter. A minimum follow-up rate of $61 \%$ was recommended for each time interval reported after surgical treatment for obesity. ${ }^{16}$

\section{Follow-up}

Follow-up data were available in 98\% (90/97) of patients at $3 \pm 3$ months, $68 \%(66 / 97)$ at 1 year ( \pm 6 months), and $26 \%$ $(25 / 97)$ at 2 years ( \pm 6 months). Patient follow-up progressively declined from 3 years onward $(18 \%, 9 \%$, and $2 \%$ at year 3,4 and 5 , respectively). The high rate of patients lost to follow-up precluded further analysis of data beyond 2 years.

\section{Outcome measure}

Excess weight (EW) pertains to the difference of the patient's actual weight and ideal body weight (IBW), expressed as

$$
E W=\text { weight }-I B W
$$

Weight loss after LAGB is calculated in terms of recommended weight calculations: ${ }^{16}$

Percentage of excess weight loss

$$
(\% E W L)=\frac{\text { baseline weight }- \text { follow up weight }}{\text { baseline weight }-I B W} \times 100
$$

Percentage of BMI reduction

$$
(\% B M I L)=\frac{\text { baseline BMI-follow up } B M I}{\text { baseline } B M I} \times 100
$$

The IBW was obtained using the following equations: ${ }^{17}$

Devine formula for males: $I B W=50 \mathrm{~kg}+2.3 \mathrm{~kg}$ for every

$$
\text { inch over } 5 \text { feet }
$$

Robinson formula for females: $I B W=49 \mathrm{~kg}+1.7 \mathrm{~kg}$ for every inch over 5 feet

The Devine formula for females gives IBW values that are generally too low, particularly for short women; the Robinson formula for males also underestimates IBW for tall men. The widely used Metropolitan Life Insurance tables for estimating IBW was not adopted in this study since it requires categorization into small-, medium- and large-frame sizes for IBW estimation. Aside from being difficult to define, the table results are too low for very short and very tall men and women. ${ }^{17}$

Successful weight loss was defined as a \%EWL of more than $50 \%$, while inadequate weight loss was a $\%$ EWL of 20 to $50 \%$. A \%EWL of less than $20 \%$ and/or band removal was considered a failed outcome. The proportions of successful weight loss at one and 2 years were used in the analysis to evaluate outcome in the intermediate term, regarded as less than 3 years.

Successful outcome after gastric banding was quantified according to the proportion of patients who lost more than $50 \%$ of their excess weight. Patients were grouped according to successful $(>50 \% \mathrm{EWL})$ or unsuccessful $(\leq 50 \%$ EWL) weight loss at one and 2 years post- surgery to determine the baseline BMI associated with a successful outcome.

\section{Statistical analysis}

Quantitative data were presented as mean \pm sd and qualitative in number and percent distribution. To determine relationships of baseline BMI with weight loss and \%EWL, Pearson correlation analysis was applied to the data. Changes in weight loss parameters from baseline to the different observation periods were carried out using paired $\mathrm{t}$ - test. To determine the association of different factors with success in weight loss, Independent t-test and Chi-square tests were used. A p-value $\leq 0.05$ was considered significant.

\section{RESULTS}

There was a total of 97 patients included in the study with a mean age of $36 \pm 12.42$ years (range of 18 to 68 ). The excess weight ranged from 26.92 to 183.31 with mean of $61.42 \pm 26.46$ kilograms. The mean BMI was $44.05 \pm 9.31$ $\mathrm{Kg} / \mathrm{m}^{2}$ with range of 32 to 92 . There were more females $(59.6 \%)$ than males (38.4\%). Majority of the subjects were from Southeast Asia (77.3\%). Fatty liver disease and dyslipidemia were among the more common comorbidities as shown in Table 1. Prediabetes was more prevalent (37\%) than type 2 diabetes mellitus (25\%). Mean $\mathrm{HbA1c}$ among those with diabetes was $7.30 \%$. 
Table 1. Baseline characteristics of patients in the study

\begin{tabular}{|c|c|}
\hline $\begin{array}{c}\text { Characteristics } \\
(n=97)\end{array}$ & $\begin{array}{c}\text { meantsd I } \\
\text { No. (\%) }\end{array}$ \\
\hline Age in years & $36 \pm 12.42$ \\
\hline Weight in kgs. & $121.80 \pm 30.91$ \\
\hline Excess weight in kgs. & $61.42 \pm 26.46$ \\
\hline Body Mass Index (BMI) & $44.05 \pm 9.31$ \\
\hline \multicolumn{2}{|l|}{ Sex } \\
\hline Male & $38(39.2)$ \\
\hline Female & $59(60.8)$ \\
\hline TOTAL & $97(100)$ \\
\hline \multicolumn{2}{|l|}{ Race } \\
\hline Southeast Asian & $75(77.3)$ \\
\hline Pacific Islander & $12(12.4)$ \\
\hline Caucasian & $10(10.3)$ \\
\hline \multicolumn{2}{|l|}{ Comorbidities } \\
\hline Fatty liver disease & $87(89.7)$ \\
\hline Dyslipidemia & $80(82.5)$ \\
\hline Hypertension & $42(43.3)$ \\
\hline Hyperuricemia/gout & $42(43.3)$ \\
\hline Prediabetes & $36(37.1)$ \\
\hline Type 2 diabetes mellitus & $25(25.8)$ \\
\hline Cigarette smoking & $24(24.7)$ \\
\hline $\begin{array}{l}\text { Obstructive sleep apnea } \\
\text { syndrome }\end{array}$ & $22(22.7)$ \\
\hline Cholelithiasis/cholesterolosis & $16(16.5)$ \\
\hline Bronchial asthma & $10(10.3)$ \\
\hline Coronary heart disease & $7(7.2)$ \\
\hline Polycystic ovary syndrome* & $6(10.2)^{*}$ \\
\hline
\end{tabular}

There were significant positive correlations between baseline BMI and excess weight at 3 months ( $\mathrm{r}=0.777), 1$ year $(\mathrm{r}=0.776)$ and 2 years (0.579) follow-up. This means that high baseline BMI value is significantly associated with high excess weight as presented in Figure 1 below.

Baseline BMI however did not show significant correlation with percent excess weight loss (\%EWL) as shown in Figure 2. There was positive trend on month 3 and negative trends on year 1 and year 2 observation periods but as mentioned the relationships were not statistically significant.

There were significant decreases in excess weight, BMI and weight from baseline to 3 months, 1 year and 2 years observation as shown in Table 2. The lowest decrease in the above mentioned variables was observed on the $3^{\text {rd }}$ month while the biggest was on the $2^{\text {nd }}$ year. The percent excess weight (\%EWL) was lowest on the $3^{\text {rd }}$ month and highest on the $2^{\text {nd }}$ year. The same trend was observed in the percent change in BMI (\%BMIL).

There was only $1(1.1 \%)$ patient who had successful weight loss ( $>50 \%$ EWL) on the 3rd month of follow-up. On the 1st and 2nd years of follow-up, 9(13.6\%) and 12(48.0\%) of the patients respectively had successful weight loss. Gastric bands were explanted in 5 patients due to bandrelated complications, yielding a band explantation rate of $5.15 \%$ at 2.6 years (range 1 to 4 years). Conversion to gastric sleeve resection was done in 2 of these patients. Band removal was considered LAGB failure in the data analysis.

Association of different factors with success in weight loss at one year observation did not show significant results except for baseline BMI as presented in Table 3. The mean baseline BMI was significantly higher in those who failed $(\leq 50 \%$ EWL) than those who succeeded $(>50 \%$ EWL). At year 2 observation, the association of baseline BMI with success in weight loss was not statistically significant.

Table 3. Association of different factors with weight loss

\begin{tabular}{|c|c|c|c|}
\hline \multirow[b]{2}{*}{ Factors } & \multicolumn{2}{|c|}{ Weight Loss at Year 1} & \multirow[b]{2}{*}{ p-value } \\
\hline & $\begin{array}{c}\text { Success } \\
>50 \% E W L \\
(n=9)\end{array}$ & $\begin{array}{c}\text { Failed } \\
\leq 50 \% \mathrm{EWL} \\
(n=57)\end{array}$ & \\
\hline Baseline BMI & $38.12 \pm 3.28$ & $44.27 \pm 7.95$ & $<0.001^{*}$ \\
\hline Age in years & $34 \pm 10.56$ & $36 \pm 12.45$ & $0.694 \mathrm{~ns}$ \\
\hline Sex & & & $0.713 \mathrm{~ns}$ \\
\hline Males & $4(44.4)$ & $20(35.1)$ & \\
\hline Females & $5(55.6)$ & $37(64.9)$ & \\
\hline \multicolumn{4}{|l|}{ Co-morbidities } \\
\hline Pre-Diabetes & $4(44.4)$ & $17(29.8)$ & $0.450 \mathrm{~ns}$ \\
\hline Diabetes Mellitus & $2(22.2)$ & $16(28.1)$ & $1.000 \mathrm{~ns}$ \\
\hline Hypertension & $2(22.2)$ & $23(40.4)$ & $0.464 \mathrm{~ns}$ \\
\hline Dyslipidemia & $8(88.9)$ & $48(84.2)$ & $1.000 \mathrm{~ns}$ \\
\hline Coronary Heart Disease & $0(0.0)$ & $3(5.3)$ & $1.000 \mathrm{~ns}$ \\
\hline Obstructive Sleep & $1(11.1)$ & 12(21.1) & $0.675 \mathrm{~ns}$ \\
\hline Apnea & $1(11.1)$ & $16(28.1)$ & $0.427 \mathrm{~ns}$ \\
\hline Smoking & $1(11.1)$ & $6(10.5)$ & $1.000 \mathrm{~ns}$ \\
\hline Bronchial Asthma & & & \\
\hline
\end{tabular}

Table 2. Assessment of weight and weight loss by observation periods

\begin{tabular}{|c|c|c|c|c|c|}
\hline $\begin{array}{c}\text { Weight / } \\
\text { Weight Loss }\end{array}$ & No. & $\begin{array}{l}\text { Baseline } \\
\text { meantsd }\end{array}$ & $\begin{array}{l}\text { Follow-up } \\
\text { mean } \pm \text { sd }\end{array}$ & $\begin{array}{c}\text { Difference } \\
\text { mean } \pm \text { sd }\end{array}$ & p-value \\
\hline \multicolumn{6}{|l|}{ Excess Weight } \\
\hline 3 months & 90 & $61.40 \pm 26.49$ & $49.85 \pm 20.72$ & $11.54 \pm 15.15$ & $<0.001^{*}$ \\
\hline 1 year & 66 & $60.53 \pm 24.24$ & $42.71 \pm 20.87$ & $17.82 \pm 14.85$ & $<0.001^{*}$ \\
\hline 2 years & 25 & $64.67 \pm 28.54$ & $36.57 \pm 23.78$ & $28.10 \pm 22.83$ & $<0.001^{*}$ \\
\hline \multicolumn{6}{|l|}{$\%$ Excess Weight } \\
\hline 3 months & 90 & & $18.01 \pm 11.04$ & & \\
\hline 1 year & 66 & & $31.47 \pm 19.39$ & & \\
\hline 2 years & 25 & & $43.84 \pm 25.09$ & & \\
\hline \multicolumn{6}{|l|}{$\mathrm{BMI}$} \\
\hline 3 months & 90 & $44.07 \pm 9.39$ & $39.90 \pm 7.27$ & $4.16 \pm 5.69$ & $<0.001^{*}$ \\
\hline 1 year & 66 & $43.43 \pm 7.76$ & $36.78 \pm 6.91$ & $6.65 \pm 4.55$ & $<0.001^{*}$ \\
\hline 2 years & 25 & $44.65 \pm 8.96$ & $34.69 \pm 7.78$ & $9.96 \pm 7.84$ & $<0.001^{*}$ \\
\hline \multicolumn{6}{|l|}{$\%$ change in $\mathrm{BMI}$} \\
\hline 3 months & 90 & & $8.80 \pm 6.71$ & & \\
\hline 1 year & 66 & & $15.06 \pm 9.07$ & & \\
\hline 2 years & 25 & & $21.54 \pm 13.39$ & & \\
\hline \multicolumn{6}{|l|}{ Weight } \\
\hline 3 months & 90 & $121.92 \pm 31.06$ & $110.34 \pm 25.61$ & $11.58 \pm 15.14$ & $<0.001^{*}$ \\
\hline 1 year & 66 & $121.08 \pm 29.96$ & $102.42 \pm 25.83$ & $18.65 \pm 13.69$ & $<0.001^{*}$ \\
\hline 2 years & 25 & $126.36 \pm 33.77$ & $98.24 \pm 28.72$ & $28.12 \pm 22.84$ & $<0.001^{*}$ \\
\hline
\end{tabular}




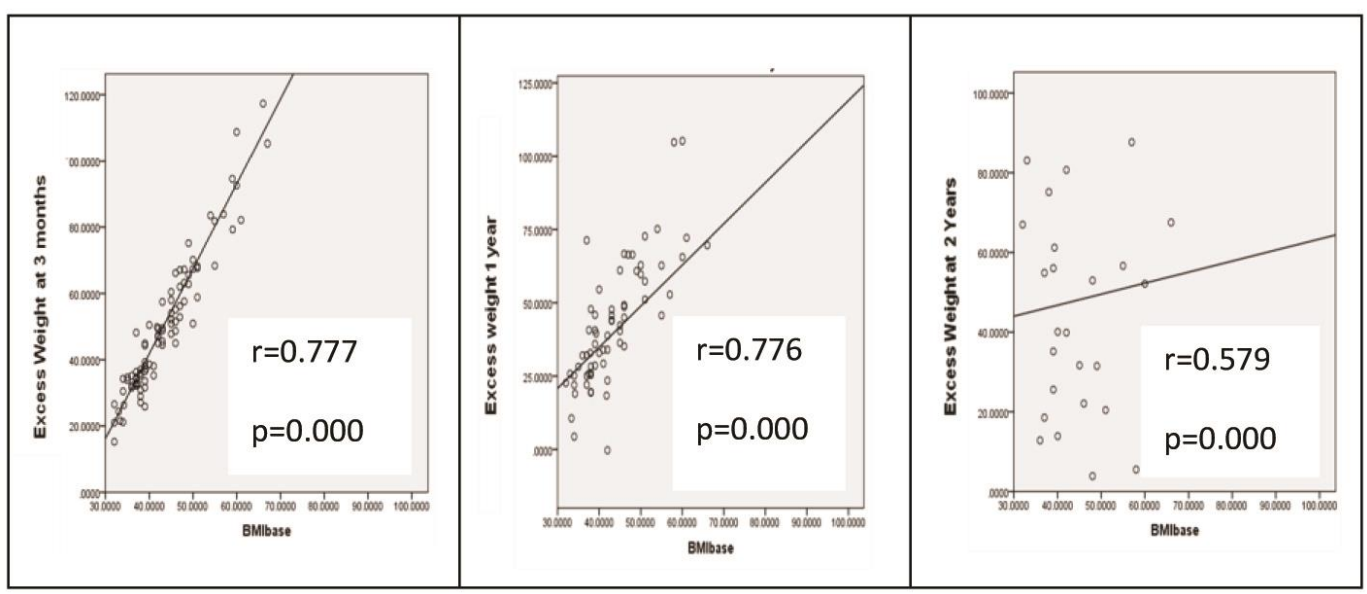

Figure1. Correlation of baseline BMI with excess weight at different observation

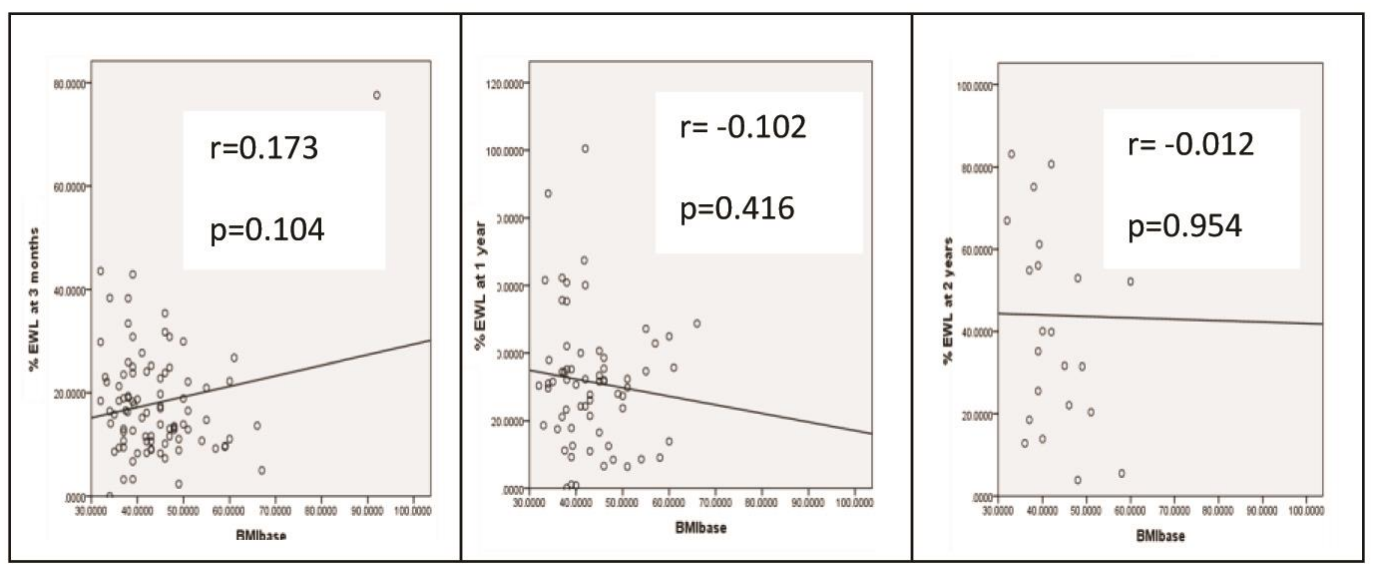

Figure 2. Correlation of baseline BMI with percent weight loss at different observation

\section{DISCUSSION}

We presented the 2-year outcome of LAGB in a series of 97 obese adults in our institution using retrospective data. In our series, a $43.84 \%$ EWL was achieved at 2 years. This is lower compared to the mean \%EWL of $50.3 \%$ at 2 years reported in a meta-analysis involving 28 studies. ${ }^{18}$ Our value is closer to the $47.5 \%$ EWL demonstrated in an earlier meta-analysis based on 12 studies. ${ }^{1}$ The majority of longterm follow-up studies also show substantial weight loss by 2 years. ${ }^{19,20,21}$

Some authors suggest that LAGB is more favorable in lower BMI and age categories.,20,23,24 A nationwide prospective study involving 1236 LAGB cases identified the following predictors of success after LAGB: (1) age less than 40 years, (2) initial BMI less than $50 \mathrm{~kg} / \mathrm{m}^{2}$, (3) experience of the surgeon, (4) performance of more than 2 procedures per week, (5) recovery of physical activity, and (6) change in eating habits. ${ }^{24}$ Similarly, we found that those who achieved successful weight loss at one year had significantly lower mean baseline BMI than those who did not. However, this was not observed on the second year. Our result was consistent with that reported by Dixon and
O'Brien, indicating that BMI more than $50 \mathrm{~kg} / \mathrm{m}^{2}$ was a predictor of poor outcome at one year but not after. ${ }^{23}$

In our cohort, a baseline BMI of $44 \pm 7.95 \mathrm{~kg} / \mathrm{m}^{2}$ identified those at risk of failure to adequately lose excess weight one year after gastric banding. Snyder reported a starting BMI more than $46 \mathrm{~kg} / \mathrm{m}^{2}$ as the cut-off above which inadequate weight loss one year after LAGB is predicted, similar to our observation. ${ }^{9}$ The effect of high initial BMI on long-term weight loss remains unclear.

The high percentage of patients lost to follow up after LAGB has been frequently observed. ${ }^{18,20,22}$ In the metaanalysis by Garb, $49.8 \%$ of LAGB patients were lost to follow-up at 2 years, growing to $82.6 \%$ at more than 3 years. ${ }^{18}$ Similar to the decline in follow-up rate over time seen in our study, another series involving 160 patients showed $65.6 \%$ follow-up at 1 year, $36.1 \%$ at 2 years, 17.6 at 3 years, $15 \%$ at 4 years, and $25 \%$ at 5 years. ${ }^{22}$ Poor patient follow-up may render outcome estimates inaccurate. Lack of patient motivation and living abroad may have influenced poor clinic follow-up. It is also speculated that those who did not return for follow-up may be doing well and would have better \%EWL than reported. 
Our study was limited by its retrospective design, high rate of dropout, and unavailable data on other potential variables that could influence outcome after LAGB. Most of the comparative literature in LAGB used retrospective data over a short time period, similar to our study. There is a paucity of long-term data because of very poor patient follow-up. In our study, we were able to gather robust results from 3 months to one year follow-up. Furthermore, the study design did not permit a standardized assessment of severity of comorbidities preoperatively, and improvement or resolution of comorbidities postoperatively. Other reported predictive factors of successful outcome, such as physical activity, eating habits, postoperative complications and other comorbidities, were also not determined.

Based on our observations, we recommend an intensive and standardized postoperative management program after LAGB to increase adherence to follow-up visits and improve weight loss outcome. We also suggest a bariatric surgery registry in our institution to increase the accuracy of reported outcomes and monitor the institution's performance in the surgical treatment of obesity. Clearly, further studies on other factors that predict the overall success of LAGB is vital. A prospective study to establish the role of gastric banding in sustaining weight loss in the long-term and in resolving or improving comorbidities is also recommended.

\section{CONCLUSION}

In the study population, obese adults achieved a substantial weight loss of $43.46 \% 2$ years after LAGB. Likewise, greater BMI reduction $(21.55 \%)$ and higher proportion of successful weight loss (48\%) were seen on the second year. Baseline BMI is significantly correlated with excess weight but not with percent weight loss. There were significant decreases in all weight parameters such as weight, excess weight, \%EWL and BMI 3 months, 1 year, and 2 years observation periods after LAGB. Low baseline BMI was associated with successful weight loss 1 year after LAGB.

\section{References}

1. Buchwald H, Avidor Y, Baunwald E et al. Bariatric surgery: A systematic review and meta-analysis. JAMA 2004;292(14):1724-37.

2. Picot J, Jones J, Colquitt JL et al. The clinical effectiveness and costeffectiveness of bariatric (weight loss) surgery for obesity: A systematic review and economic evaluation. Health Technol Assess 2009;13(41):1-190.

3. O'Brien PE, Dixon JB, Laurie C et al. Treatment of mild to moderate obesity with laparoscopic adjustable gastric banding or an intensive medical program: A randomized trial. Ann Intern Med 2006;144(9):625-33.

4. Hinojosa MW, Varela JE, Parikh D et al. National trends in use and outcome of laparoscopic adjustable gastric banding. Surg Obes Relat Dis 2009;5(2):150-5.

5. Snyder B, Wilson T, Mehta S et al. Past, present, and future: Critical analysis of use of gastric bands in obese patients. Diabetes Metab Syndr Obes. 2010;3:55-65.

6. Dineros $H$, Sinamban $R$, Siozon $M$ et al. Obesity surgery in the Philippines: Experience in a private tertiary hospital for years 2002 to 2004. Obes Surg 2007;17(1):82-7.
7. Tin Hay L, Oliveros E, Esguerra E et al. A review of the metabolic profile of patients undergoing bariatric surgery in St. Luke's Medical Center. Phil J Int Med 2004;43(6):323-33.

8. Chau W, Schmidt H, Kouli W et al. Patient characteristics impacting excess weight loss following laparoscopic adjustable gastric banding. Obes Surg 2005;15(3):346-50.

9. Snyder B, Scarborough T, Yu S, Wilson E. Failure of adjustable gastric banding: Starting BMI of $46 \mathrm{~km} / \mathrm{m}^{2}$ is a fulcrum of success and failure. Surg Obes Relat Dis 2009;5(3):310-6.

10. Toouli J, Kow L, Ramos AC et al. International multicenter study of safety and effectiveness of Swedish Adjustable Gastric Band in 1-, 3-, and 5-year follow-up cohorts. Surg Obes Relat Dis 2009;5(5):598-609.

11. Wölnerhanssen B, Peters T, Kern B, et al. Predictors of outcome in treatment of morbid obesity by laparoscopic adjustable gastric banding: Results of a prospective study of 380 patients. Surg Obes Relat Dis 2008;4(4):500-6.

12. Mechanick JI, Kushner RF, Sugerman HJ et al. American Association of Clinical Endocrinologists, The Obesity Society, and American Society for Metabolic \& Bariatric Surgery medical guidelines for clinical practice for the perioperative nutritional, metabolic, and nonsurgical support of the bariatric surgery patient. Endocr Pract 2008;14(Supp 1):1-83.

13. Fried M, Hainer V, Basdevant A et al. Interdisciplinary European guidelines on surgery of severe obesity. Obes Facts 2008;1(1):52-9.

14. American Diabetes Association. Standards of medical care in diabetes - 2011. Diabetes Care 2011;34(Supp 1):S1-61.

15. National Cholesterol Education Program. Third report of the National Cholesterol Education Program Expert Panel on detection, evaluation, and treatment of high blood, cholesterol in adults (Adult Treatment Panel III). National Heart, Lung, and Blood Institute, National Institutes of Health Publication No. 02-5215. National Institutes of Health, 2002. http://www.nhlbi.nih.gov/guidelines/ cholesterol/atp3full.pdf.

16. American Society for Bariatric Surgery Standards Committee 20042005. Guidelines for weight calculations and follow-up in bariatric surgery. Surg Obes Relat Dis 2005;1(1):67-8.

17. Halls SB. Arithmetic formulas for calculating ideal body weight http://www.halls.md/ideal-weight/devine.htm. Accessed November 20, 2011.

18. Garb J, Welch G, Zagarins S et al. Bariatric surgery for the treatment of morbid obesity: A meta-analysis of weight loss outcomes for laparoscopic adjustable gastric banding and laparoscopic gastric bypass. Obes Surg 2009;19(10):1447-55.

19. Dargent J. Surgical treatment of morbid obesity by adjustable gastric band: The case for conservative strategy in the case of failure-a 9year series. Obes Surg 2004;14(7):986-90.

20. Weichman K, Ren C, Kurian M et al. The effectiveness of adjustable gastric banding: A retrospective 6-year follow-up study. Surg Endosc 2011;25(2):397-403.

21. Ponce J, Paynter S, Fromm R. Laparoscopic adjustable gastric banding: 1,014 consecutive cases. J Am Coll Surg 2005;201(4):529-35.

22. Michalik M, Lech P, Bobowicz M, Orlowski M, Lehmann A. A 5-year experience with laparoscopic adjustable gastric banding-focus on outcomes, complications, and their management. Obes Surg 2011; 21:1682-1686.

23. Dixon JB, O'Brien PE. Selecting the optimal patient for LAP-BAND placement. Am J Surg 2002;184(6B):17S-20S.

24. Chevallier JM, Paita M, Rodde-Dunet $\mathrm{MH}$ et al. Predictive factors of outcome after gastric banding: A nationwide survey on the role of center activity and patient's behavior. Ann Surg 2007;246(6):1034-9. 